\title{
Technical Solutions for Improving the Safety of Housing and Communal Services
}

\author{
Yulia Galitskova ${ }^{1, *}$, and Mikhail Balzannikov ${ }^{2}$ \\ ${ }^{1}$ Samara State Technical University, Institute of Architecture and Civil Engineering, \\ 194,Molodogvardeyskaya St., 443001, Samara, Russia. \\ ${ }^{2}$ Samara State University of Economics, 141 Sovetskoi Armii St., 443090, Samara, Russia
}

\begin{abstract}
The article reports that one of the priority areas for the implementation of the Strategic Plan for the Development of the Housing and Communal Services of Russia for the period up to 2020 is the implementation of the most effective technologies used in the construction of public infrastructure facilities and the modernization of housing stock. Certain aspects of this strategy were considered by the authors in relation to urban facilities located in the riverbank zone of the large, high-water Volga River. The current condition of the riverbank zone near the city of Samara has been analyzed. Factors adversely affecting the riverbank slope and those influencing the change in conditions of its use are singled out. The authors have registered an increasing level of safety problems for urban facilities due to the loss of the slope stability. As possible measures to improve the stability of the slope and ensure environmental safety, technical and technological solutions developed with the participation of the authors are recommended.
\end{abstract}

\section{Introduction}

At present, the Russian Federation is implementing the Strategic Plan for the Development of Housing and Communal Services for the Period up to 2020. The state authorities of the subjects and local governments are recommended to use the provisions of the Strategy as a guide when developing regional programs regarding housing and communal services. Among the priority complex tasks of state policy in the housing and communal sector, the Strategic Plan also mentions:

- implementation of the most effective technologies used in redesign (and construction) of communal infrastructure facilities and the modernization of housing stock;

- upgrade and improvement of energy efficiency of housing and communal service facilities.

Innovative technological solutions and advanced components, used in the course of repair and construction works on housing and communal service facilities, can significantly improve the operational characteristics of the structure (improve reliability, durability and economic efficiency), as well as improve the environmental safety of the facility [1-5].

* Corresponding author: galickova@yandex.ru 
Taking into consideration the importance of this area of focus, for many years, the team of scientists, under the guidance and with direct participation of the authors, has constantly been working on improving the designs of constructions and the technologies for their erection. The largest number of technical and technological solutions developed relate to the housing sector and the territories adjacent to the city [6-9].

\section{Materials and Methods}

Particular attention in research is paid to urban areas adjacent to water bodies, in particular - to the territories of the bank slope of the Volga River within the city of Samara. These zones acted as the direct objects of research. The stability of the riverbank, its environmental safety was chosen as the subject of the study.

The analysis of long-term observations of the river levels, the characteristics of the seasonal floods, and the analysis of actual observations of the state of the riverbank slope were used as the method of research $[7,8]$.

Features of the territory under consideration (Figure 1) are the following. Samara is a city with population exceeding one million. It stretches along the left bank of the most abundant river in the European part of the country. The city limits extend for more than 30 $\mathrm{km}$. The city is located opposite the Samarskaya Luka National Park. After the construction of the Saratov hydro power plant (erected downstream), the considered stretch of the river formally became part of the Saratov Reservoir. The river Sok empties into the Volga to the north of the city, and the river Samara - to the south.

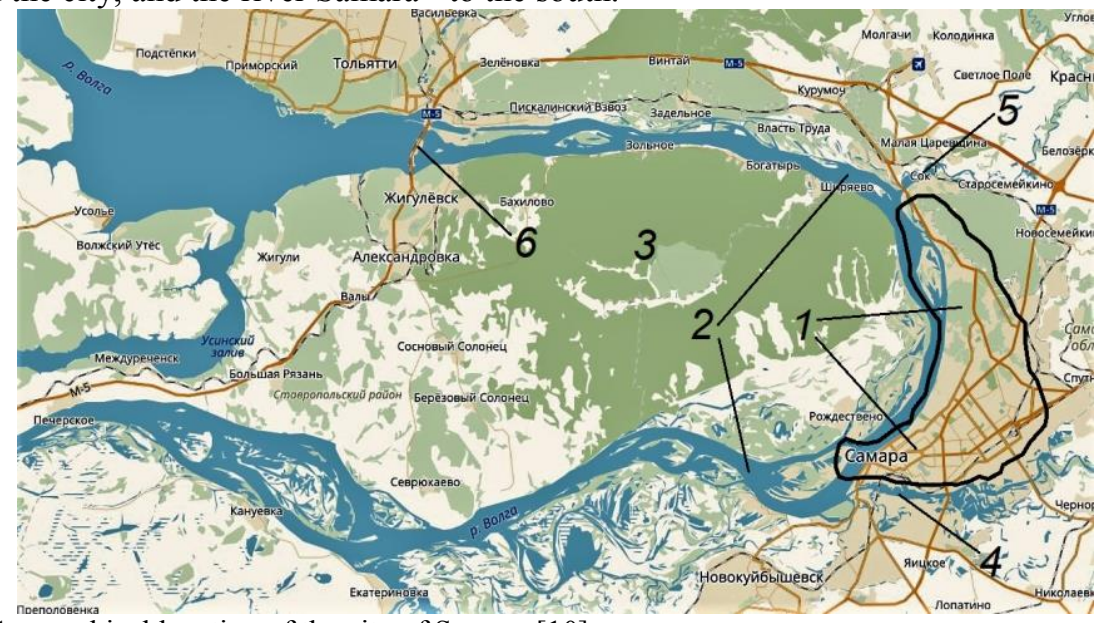

Fig. 1. Geographical location of the city of Samara [10]:

1 - limits of the city, 2 - the Volga River, 3 - the territory of Samarskaya Luka National Park, 4 - the Samara River, 5 - the Sok River, 6 - Kuibyshev Hydraulic Unit.

At the same time, where the city is located, the bank of the Volga River has a concave shape, and after filling the Saratov reservoir, the river water level rises by approximately one meter.

\section{Results}

As a result of long-term field observations and studies of the state of the bank slope in the vicinity of the Samara city, the following is revealed. After filling the Saratov reservoir, the natural level of water in the river has changed and the river's water surface area has increased which triggered the adaptation of the bank slope, as well as a rise in the level of 
groundwater within the slope. The adaptation of the bank slope is caused both by wind waves and by the eroding transverse circulation of the water flow due to the bending riverbed. Figure 2 exemplifies the above-mentioned effect.

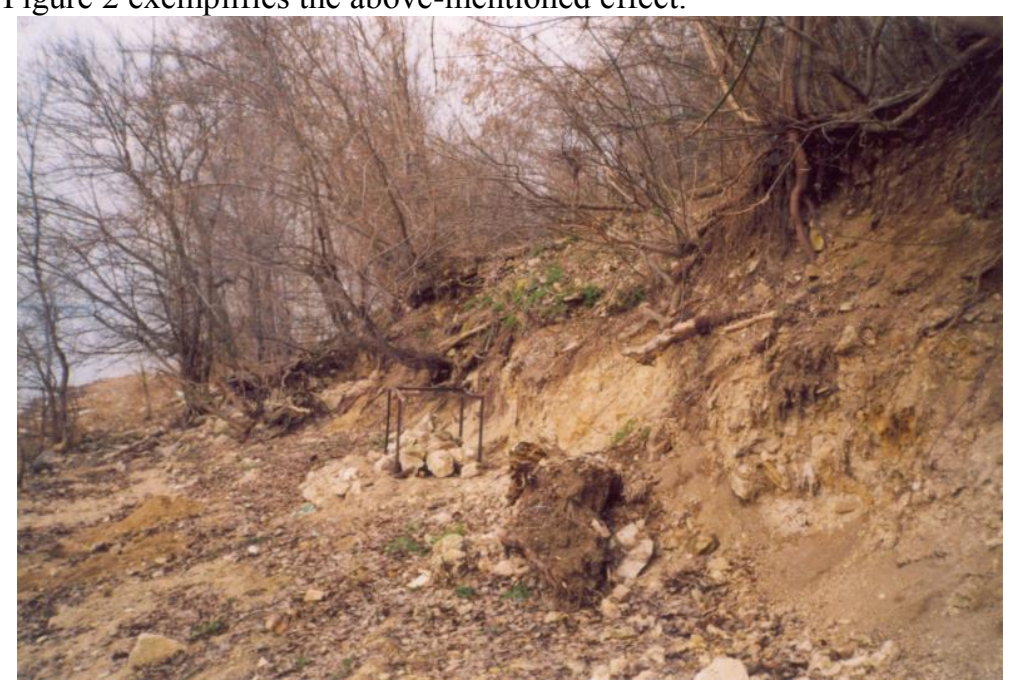

Fig. 2. General view of the destroyed river bank slope due to the impact of waves (photo of the authors)

Moreover, the observational analysis has shown that the rise in the level of groundwater is considered the most dangerous factor, since it can cause a large section of the bank slope lose its stability. Thus, in the Krasnoglinsky district of the Samara city, a large section of the riverbank collapsed (Figure 3). The loss of stability of the riverbank is caused by the rise of the groundwater level triggered by the simultaneous influence of a number of factors. Among them are: the discharge of flood waters through the weir dam of the Kuibyshev hydroelectric complex with rising level of water in the river, a long period of rainfall, leaks from the city water supply network. The situation was especially dangerous due to the residential buildings located in the immediate vicinity. In order to ensure their safety, the residents of these buildings were evacuated in a timely manner.

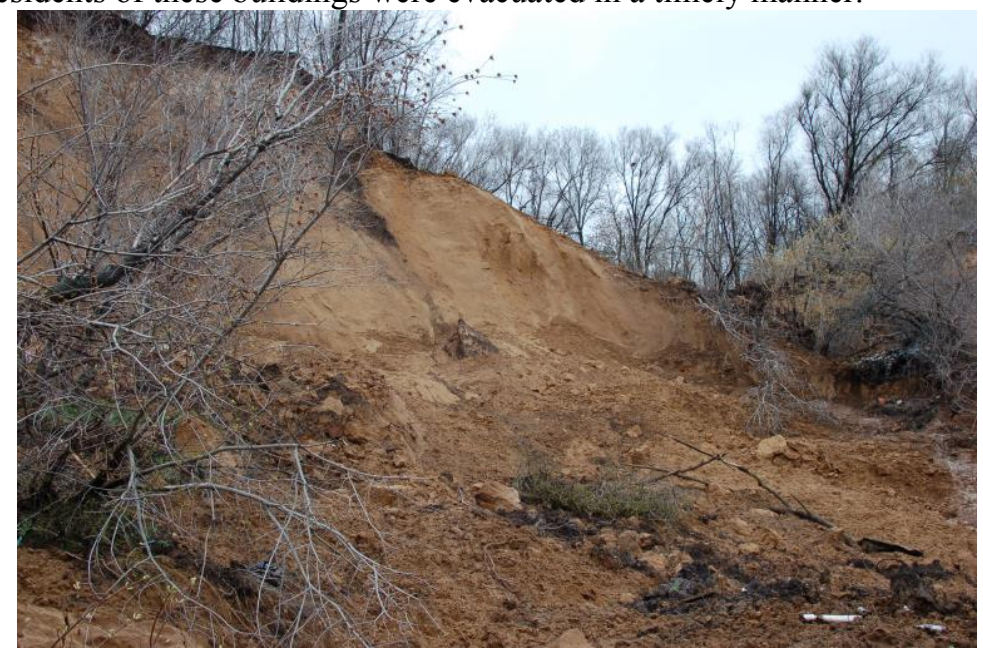

Fig. 3. General view of the destroyed riverbank slope due to the loss of stability (photo of the authors) 
It should be noted that, in addition to the factors noted above, the rise in the groundwater level is influenced by the high-rise residential buildings under construction in the riverbank zone. Deeply buried foundations of such buildings alter the previously formed groundwater paths, and the thinning groundwater layer causes an additional rise in groundwater levels.

The study of the situation also exhibited the presence of extensive equipped beaches directly within the city area. Many people spend their free time in this recreational area in summer. The possible loss of stability and the collapse of the exposed riverbank slope upstream, together with the release of wastes into the river, can for a long period deprive the citizens of the opportunity to rest on the beach and the embankment.

Thus, the performed analysis showed the importance and necessity of developing technical solutions aimed at ensuring the safety of urban facilities located within the zone of influence of the river slope.

Depending on the area of their influence, all technical solutions can be divided into two categories: local (or point) solutions and geographically distributed (or zonal).

Local activities provide an increase in technical and environmental safety against the adverse impact of an object that has fixed, non-extended dimensions in plan view. For example, the authors have developed the method for protecting the environment [6] to be used in the process of repairing block or panel houses. This technical solution involves the arrangement of technological holes of two types: main holes in the dismantled wall block and auxiliary holes in the adjacent wall blocks (RF 2369706 patent), as well as the use of intercepting trays with a protective screen.

The method of protecting the environment from pollution by domestic and industrial waste (RF 2294245 patent) can also be related to the category of local solutions. The technical solution ensures the reduction of soil and atmosphere pollution in the areas with landfills of domestic and industrial waste and the adjacent territories. To achieve the goal, the use of a protective barrier in the ground and on its surface is envisaged. As an upgrade for the developed solution about the way of protecting environment from solid domestic waste (RF 2372154 patent), equipping special areas for organized storage of solid human waste was additionally proposed [6].

Another example of an innovative technical solution is the method of environmental protection (RF 2411334 patent) which proposes using foam generators to reduce the pollution of air and the adjacent territory while conducting works on dismantling or reconstruction of the facility [6]. The method is recommended for application while carrying out works within the city limits, conservation districts and near water bodies (rivers, lakes). The proposed method will allow disassembling the structural elements of the building without spreading dust over the adjacent territory.

Geographically distributed (or zonal) innovative solutions make it possible to protect larger areas. Thus, within the method for protecting the bank slope from destruction (RF 2237129 patent), a solution has been proposed to protect the extended riverbank slope from loss of stability [6]. The set goal is achieved by lowering the level of groundwater saturating the bank slope. For this purpose, the drainage elements with intermediate and dead-end sections are installed in the body of the slope. The sections are arranged in one or several levels in height, and each section consists of a working and a diverting part. These drainage elements provide a controlled collection of groundwater in the slope and their diversion to a nearby pond.

The method of protecting a water body from pollution (RF 2441963 patent) can be related to the same group of solutions. It provides a technical solution for protection against the impact of solid anthropogenic wastes generated along the bank slope. Fig. 4 illustrates an example of such formations. 


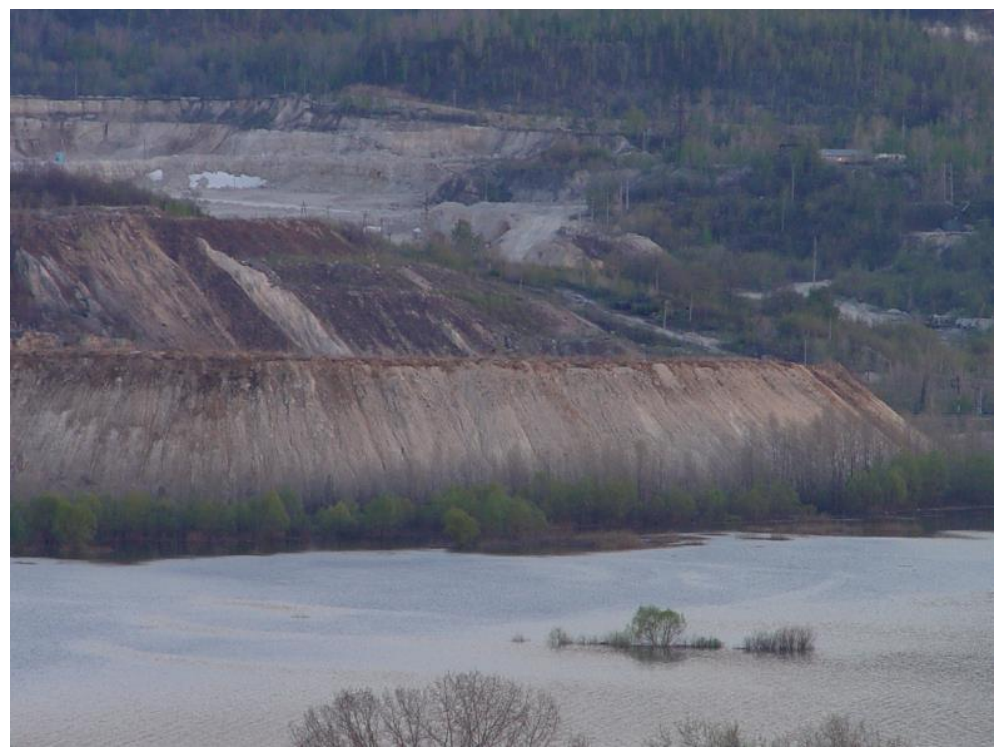

Fig. 4. General view of anthropogenic waste on the riverbank slope (photo of the authors)

The developed method involves the installation of both open-cut and closed drainage elements. Open-cut drainages are arranged as internal and external collecting ditches, while closed drainages are arranged as pipes buried in stored solid waste. The top level of stored solid waste is arranged in two layers with bottom level containing drainage material and top - waterproof material.

\section{Discussion}

The above-mentioned long-term technical solutions and measures to improve the reliability of the facilities and ecologically safe use of the territory directly in the urban zone of the riverbank testify to the necessity for an integrated approach for solving modern environmental problems. Such an approach must necessarily include the detailed monitoring of the groundwater flow and movement of the coastal zone, careful calculations of the stability of the most dangerous areas of the riverbank slope with various combinations of emerging conditions and effects.

Only after detailed studies of the situation should the engineering activities follow. The great importance of technical solutions lies in the fact that they allow to ensure the safety of operation of urban housing facilities.

The measures examined are not equivalent in scale or financial costs connected with their implementation. In this regard, activities of the local level can be recommended for implementation first.

\section{Conclusions}

The analysis of the up-to-date state of the urban territory adjacent to the Volga River and the developed technical solutions for improving the safety of urban facilities allow us to formulate the following main conclusions:

1. Constant monitoring for the stability of the bank slope and the ecological state of the waterside areas of the high-water rivers is needed, especially when the river bank area is packed with municipal facilities. 
2. In order to ensure the safety of urban facilities located in the riverbank zone, it is important to develop and implement well-timed effective technical, technological and organizational measures to protect these facilities.

3. Depending on the area of their influence, technical solutions can be divided into two categories: local (or point) solutions and geographically distributed (or zonal). As a priority, the authors can recommend activities of the local level due to their lower costs and relatively short implementation time.

\section{References}

1. V. G. Sebeshev, Higher Educational Institutions Newsletter. Building 6, 18 (2016)

2. T. V. Dormidontova, A. V. Filatova, Industrial and Civil Construction 6, 4 (2015)

3. A. A. Mikhasek, M. V. Rodionov, M. G. Litvinova, Urbanism and Architecture 3 (28), 5 (2017)

4. I. S. Kholopov, M. I. Balzannikov, V. Yu. Alpatov, A. V. Soloviev, Procedia Engineering 153, 5 (2016)

5. I. S. Sobol, Privolzhsky Scientific Journal 2 (26), 2 (2003)

6. T. V. Belova, A. A. Bolotova, MSCU Bulletin 4, 9 (2013)

7. Yu. M. Galitskova, A. A. Mikhasek, MATEC Web of Conferences, 117 (2017)

8. M. I. Balzannikov, Yu. M. Galitskova, N. V. Akhrameeva, S. V. Shlomov, Industrial And Civil Construction 6, 4 (2014)

9. A. Smyvalov, M. Rodionov, Yu. Galitskova, MATEC Web of Conferences, 117 (2017)

10. https://www.google.com/maps/@53.2569969,49.8621165,9.74z?hl=ru-RU 